\title{
Leading practice waste dump rehabilitation at the Ginkgo mineral sands mine
}

\author{
H. Squires Landloch Pty Ltd, Australia \\ M. Priest Bemax Resources Limited, Australia \\ I. Sluiter Ogyris Pty Ltd; and The University of Ballarat, Australia \\ R. Loch Landloch Pty Ltd, Australia
}

\begin{abstract}
Bemax Resources Ltd operates the Ginkgo mineral sands mine located $35 \mathrm{~km}$ west of Pooncarie in far western New South Wales. Large 'start-up' overburden stockpiles are present at the mine site and will remain after closure. The first overburden stockpile to be constructed and revegetated is overburden stockpile OB3, which covers an area of 34 ha.

Material characterisation studies by Landloch Pty Ltd provided detailed information on runoff and erosion potential of the outer batter slopes, underpinning recommendations with respect to batter profiles, heights, and gradients, and surface treatments such as placement of tree debris to control wind and water erosion. Associated trials have shown the value of tree debris in reducing impacts of sand movement on emerging seedlings. Perimeter and cross bunding to manage runoff from the top of the landform were also recommended.
\end{abstract}

Soil stripping operations have followed a two-step process, using tractors towing laser scoop buckets to ensure accurate collection and placement of topsoil and subsoil layers. Stockpile management aimed to minimise deterioration of topsoil properties, though significant changes in a range of soil parameters have been documented, leading to some modification of existing practices. Vegetation studies guided development of seed mixes for direct seeding, which was carried out using a dozer-mounted drum seeder able to work through the tree debris.

The initial seeding shows excellent stability to erosion, and observations have confirmed the importance of perimeter bunding. Initial soil and vegetation monitoring confirms establishment of a chenopod shrubland vegetation at the desired indigenous plant cover levels, but has identified a need for improvement of soil fertility in subsequent rehabilitation operations (continuing improvement is essential).

Data from the various stages of design, rehabilitation and monitoring are presented to illustrate the range of areas to be addressed if rehabilitation is to be successful.

\section{Introduction}

Mine site rehabilitation represents not only a significant cost for mining operations, but also a key criterion by which communities judge the environmental performance of the mining industry as a whole.

The costs of rehabilitation can vary greatly, and can be further increased if there is a need to re-work, repair, or remediate failed rehabilitation works. The costs of failed or unsatisfactory rehabilitation are considerable; topsoil may not be readily available (seldom is there sufficient topsoil for more than one attempt at rehabilitation), access may be difficult, and once in place, a poor landform design is difficult to modify. 
Successful mine site rehabilitation requires a high standard to be maintained across all components of the process, from planning through to execution and monitoring. Failure to achieve high standards in only one component of the project may be sufficient to cause overall failure.

Well planned and executed rehabilitation does not guarantee success. Extreme rainfall events are always possible, but adoption of leading practices regularly achieves considerable reductions in rehabilitation costs, and strongly increases the probability of success. It makes sound economic sense to get mine site rehabilitation right the first time.

This paper details the rehabilitation methods applied at the Bemax Ginkgo Mine, and the results achieved by its combination of sound science and sound construction practices to achieve cost-effective and excellent rehabilitation outcomes.

\section{$1.1 \quad$ The Ginkgo Mine}

The Bemax Ginkgo Mine is located $35 \mathrm{~km}$ west of Pooncarie in Far Western NSW. Development approval for the Ginkgo Mine was issued in 2002, and mining commenced in late 2005 after a 10 month construction period.

The Ginkgo Mine is located in the Murray Basin; a sedimentary basin covering $300,000 \mathrm{~km}^{2}$ of inland South East Australia. The Ginkgo Mine is a mineral sands deposit comprised of a series of shallow marine beach, dune, estuarine, and fluvial sands with accumulations of the valuable heavy minerals ilmenite, rutile and zircon.

The overburden at Ginkgo is on average $30 \mathrm{~m}$ deep and consists of clay and sandy clay materials. During the start up of the dredge mine, and until the dredge pond has reached sufficient length to allow back filling of the dredge pond, the overburden is placed in permanent overburden stockpiles. At the Ginkgo Mine there are three permanent waste dumps which are predominantly clay material, a sand tailings dam and a slurried sand overburden dam. The waste dumps, including the sand dams at Ginkgo, cover an area of approximately 160 ha.

\section{$1.2 \quad$ Initial observations of erosion potential}

Previous landforms at Ginko Mine appeared to have had little limitation on height, and were constructed with $20 \%$ gradient outer batter slopes. The batters were compacted (which increases runoff) and showed rilling in some areas (Figure 1). A massive gully, on a landform that had no design or batter shaping considered with respect to stability, can be seen in Figure 2. Some batter slopes also showed evidence of tunnel erosion (Figure 3 ) indicating that care needed to be taken with management of surface water, and with ponding and deep drainage in the profiles that were created.
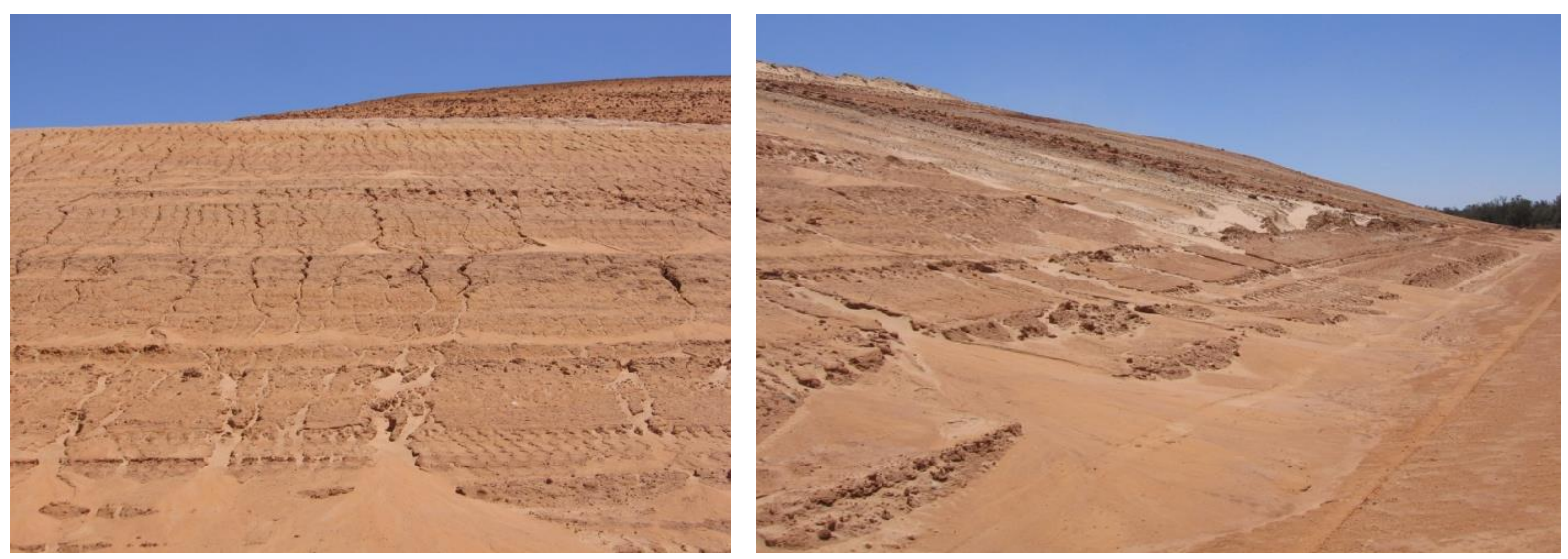

Figure 1 Rilled batter slope on waste dump 


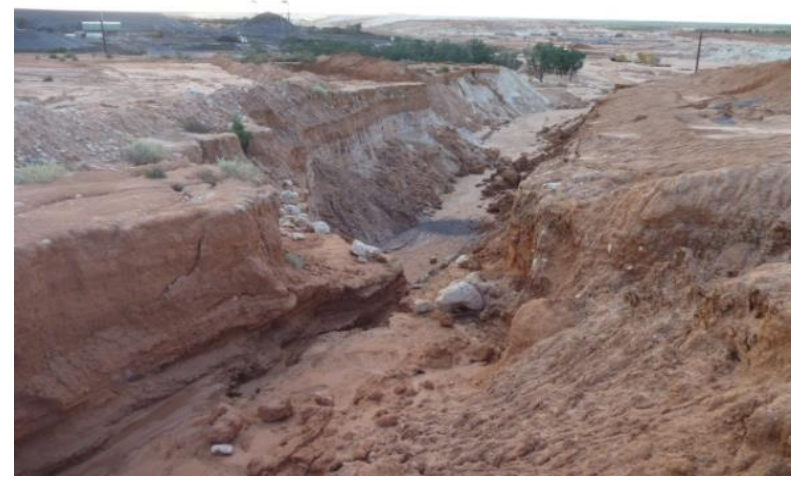

Figure 2 Massive gully erosion in an existing waste dump where no design and batter shaping has taken place

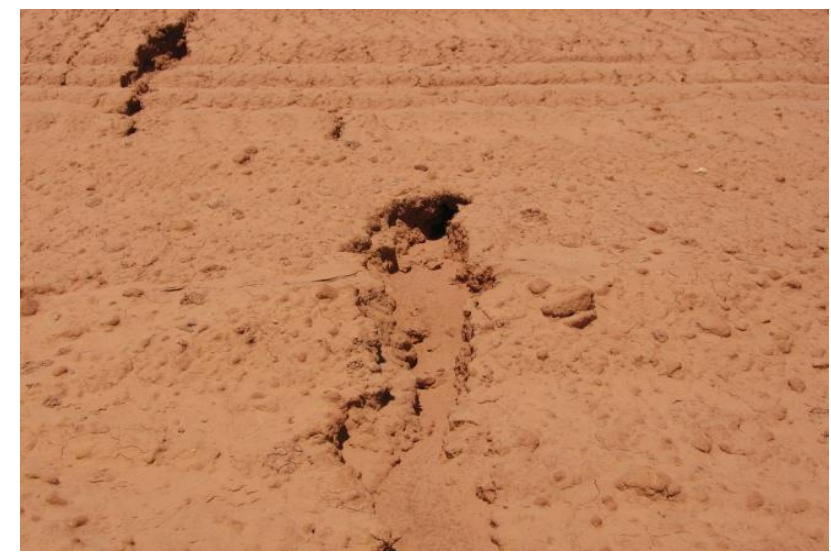

Figure 3 Tunnel erosion on waste dump batter

It was concluded that:

- In the absence of hard-setting or consolidation, the loamy topsoil (when bare) has low resistance to rill development.

- Once established, eroding batter slope systems (rills, gullies) have little potential to stabilise through time, as the materials have virtually no rock content and no potential to armour. Hence, incision could eventually reach considerable depths in the landforms.

\section{Rehabilitation planning}

Planning is an essential component of waste dump rehabilitation. Priorities and issues can vary from site to site, but planning typically includes:

- Characterisation of soils and wastes.

- Definition of goals for the rehabilitated landform.

- Preparation of landform design.

- Identification of plant species required.

- Assessment of soil fertility needs and amendments.

- Consideration of any other specific issues critical for rehabilitation success.

For the Ginkgo Mine, a range of studies were carried out to address these requirements. 


\subsection{Material characterisation and erosion modelling}

Topsoil and subsoil were analysed, and their properties pertaining to soil stability are shown in Table 1 . The analytical data indicate relatively slight differences between topsoil and subsoil, consistent with the profile being originally deposited of relatively uniform sandy loam material with some slight subsequent stratification due to plant growth.

\section{Table 1 Soil properties of the $<10 \mathrm{~mm}$ fraction of samples tested}

\begin{tabular}{lcc}
\hline Property Analysed & Topsoil & Subsoil \\
\hline $\mathrm{pH}$ & 8.7 & 9.4 \\
$\mathrm{EC}_{1: 5}(\mathrm{dS} / \mathrm{m})$ & 0.36 & 0.18 \\
$\mathrm{ESP}$ & 12.5 & 8.6 \\
Coarse sand (\%) & 42 & 50 \\
Fine sand (\%) & 36 & 29 \\
Silt (\%) & 4 & 4 \\
Clay (\%) & 18 & 17 \\
\hline
\end{tabular}

Note: Soil properties in detail:

$\mathrm{EC}=$ Electrical conductivity, a measure of soil salt content.

ESP = Exchangeable Sodium Percentage (Exchangeable Sodium as a percentage of total Cation Exchange Capacity).

The sodicity (ESP $>6 \%$ ) of the topsoil suggests that surface sealing under rain and crusting on drying could be expected, and that there may be potential for tunnel erosion if the material is placed in a manner such that site conditions (significant depth and duration of ponding at specific points) favour the development of tunnelling. This is consistent with the observations made on site of tunnel erosion.

To determine the optimum shape of the batter slope, runoff and erosion models were used. Infiltration capacity and erodibility of the topsoil and subsoil were measured using laboratory techniques developed by Landloch. Erodibility parameters required for the WEPP (Water Erosion Prediction Program) model (Flanagan and Livingston, 1995) are $K_{i}$ (interrill erodibility), $K_{R}$ (rill erodibility), and $\tau_{c}$ (critical shear for rill initiation).

Also important is a hydraulic conductivity $\left(\mathrm{K}_{\mathrm{e}}\right)$ parameter used in the model to predict runoff. Use of sitespecific erodibility parameters is crucial in the development of effective landform designs. Simulations of runoff and erosion for a range of slope shapes were carried out using the WEPP model using a climate file developed on the basis of data from the Bureau of Meteorology's weather stations at Pooncarie and Mildura as not all pluviograph and temperature data were measured at other nearby sites.

Effects of batter height and gradient on predicted annual erosion rates are shown in Figure 4. The figure plots erosion against elevation relative to the surrounding land, with the top of the slope being an elevation of $30 \mathrm{~m}$.

The data show a very strong pattern of rill erosion initiating at a vertical elevation of approximately $25 \mathrm{~m}$, consistent with fall of $5 \mathrm{~m}$ vertical from the top of the slope; and rill erosion rapidly reaching a maximum, and then reducing slightly to an almost constant value for the remainder of the slope.

The data indicate a situation where the overland flow (in rills) rapidly loads with sediment to its transport limit, with erosion rates on the remainder of the slope then being determined by that transport limit. Increasing gradient increases the sediment transport capacity of the flow, thereby increasing predicted erosion rates. It should be noted that interrill erosion - which would be the dominant erosion process on the top 2-4 m vertical interval of the slope - is extremely low relative to rill erosion. 


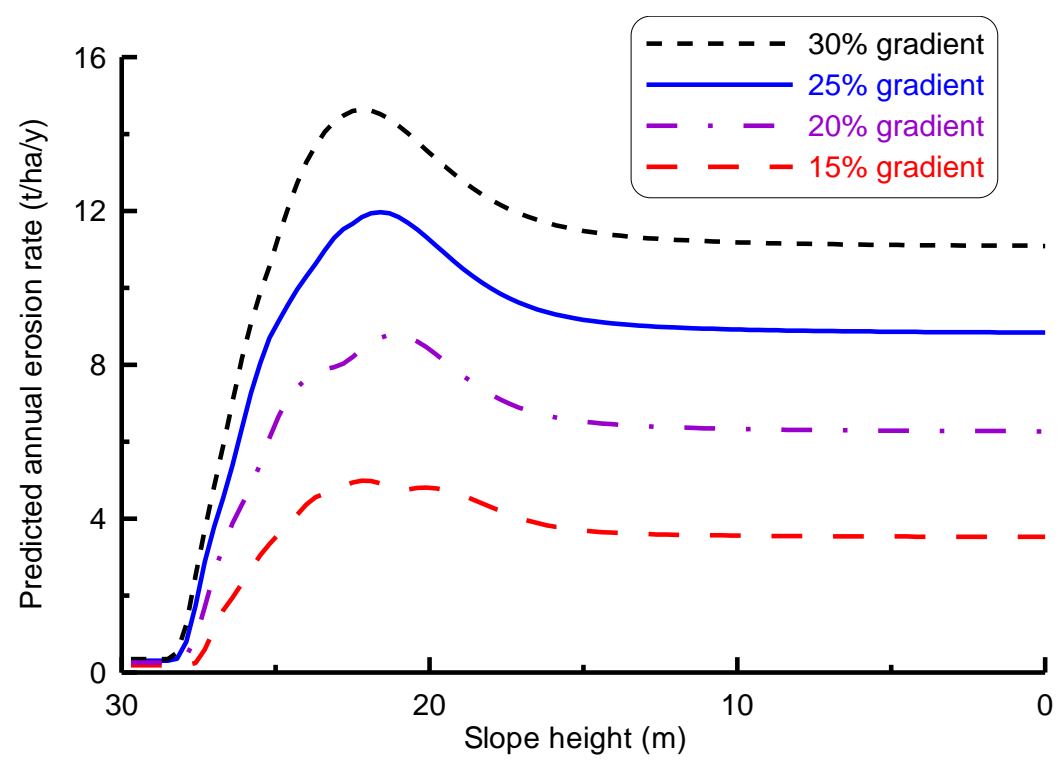

\section{Figure 4 Predicted annual rates of erosion on a $30 \mathrm{~m}$ high slope of topsoil, for a range of slope gradients}

Factors that were considered for reducing predicted erosion rates for these materials are:

- Reduction in slope gradient.

- Increased surface cover by tree debris.

- Increased surface cover by vegetation.

Effects of increasing surface cover can be considerable. The Revised Universal Soil Loss Equation (RUSLE) (Renard et al., 1997) was used to estimate cover factors for slope surfaces with differing levels of tree debris and established vegetative cover. Cover factors are also referred to as Soil Loss Ratios or C-factors, and are effectively the ratio of soil loss from the covered situation to soil loss from bare soil. Effectively, a cover factor of e.g. 0.5 indicates that cover will provide a $50 \%$ reduction in soil loss relative to bare soil.

Temporal considerations showed clearly that attempts to stabilise batter slopes without placement of tree debris carried a high risk of erosive failure, as the C-factor would be high initially, and would only decline to levels of approximately 0.4 in response to soil consolidation.

In contrast, if at least $20 \%$ tree debris cover could be spread, then the initial C-factor may be as low as 0.35 , subsequently reducing to 0.2 as grass cover established. This approach carried a much lower risk of erosive failure during the initial stages of rehabilitation, and a $20 \%$ gradient batter slope with a cover factor of 0.2 was predicted - in the long term - to produce average annual erosion rates $<2 \mathrm{t} / \mathrm{ha} / \mathrm{y}$. Placement of tree debris, therefore, offered potential to achieve acceptable erosion rates on the $20 \%$ gradient slopes planned. It would also improve vegetation establishment and provide habitat complexity for return of small vertebrates.

\subsection{Managing the risks to landform stability from tunnel erosion}

The topsoil and subsoil are sodic. The presence of dispersible clay and the lack of cohesive strength typically associated with sandy loam texture mean that the potential for this material to tunnel is quite high. Tunnels, once formed, would develop until the roofs of the tunnels collapsed to form instant gullies.

In the unconsolidated material used to construct the landforms, there is potential for any major gullies that form to incise to considerable depth, and they would have little potential to stabilise without intervention of some form. However, the risk of tunnel erosion could be virtually eliminated if ponding at any point on the landform was minimised or eliminated. Therefore, cross-slope berms that could result in ponding of 
water on batter slopes were not considered, and cross-slope ripping on batters was recommended to not produce furrows any deeper than $150 \mathrm{~mm}$.

\subsection{Vegetation studies}

Within the Ginkgo MLA area, four types of Southwest New South Wales vegetation communities (Benson et al., 2006) are typical:

- ID58 Black Oak - Western Rosewood open woodland on deep sandy loams of Murray-Darling Depression and Riverina Bioregions.

- ID221 Black Oak - Pearl Bluebush open woodland of the sandplains of the semi-arid warm and arid climate zones.

- ID154 Pearl Bluebush low open shrubland of the arid and semi-arid plains.

- ID165 Derived corkscrew grass grassland/forbland on sandplains and plains in the semi-arid (warm) climate zone.

In terms of dominance, the two woodland plant communities dominated by Belah/Black Oak (Casuarina pauper) and Rosewood (Alectryon oleifolius subsp. canescens) along with Pearl Bluebush (Maireana sedifolia) shrublands are the most important plant communities. The structural assessments provided the information necessary to design the revegetation monitoring programs so that the newly created vegetation reflects - as much as possible - the vegetation found in the surrounding area, whilst also providing habitat for the wildlife. Of particular importance are tree type and size class, number of large bluebush shrubs per hectare, plant cover along with other ground flora attributes (cover of bare ground, cryptogams and litter).

\section{Rehabilitation operations}

The waste dumps at Ginkgo were initially built with steeper batters, as per EIS requirements, with maximum storage capacity utilised and little thought for long-term rehabilitation objectives.

However, on the basis of landform design studies, the slope profile was reduced to a 1:7 (14.3\%) gradient to improve the probability of rehabilitation success. Currently, all Bemax waste dumps are constructed to the final rehabilitated profile, which results in huge cost savings for rehabilitation earthworks.

The landform design and shaping at Ginkgo has followed three basic principles:

- Stability.

- Water capture.

- Cost minimisation.

\subsection{Topsoil stripping and stockpiling}

The topsoil stripping program at Ginkgo consists of clearing the vegetation 12 months in advance, which allows the soils to consolidate after being disturbed by the dozers during the clearing process. This also allows seed set of much of the annual plants after disturbance.

The topsoil is stripped with a laser bucket fleet of tractors which have GPS control installed. This GPS has an accuracy of $+/-25 \mathrm{~mm}$, which allows precision stripping of soil layers. The soil is generally stripped in two layers, topsoil and subsoil, which are stockpiled separately.

The soil stockpiles are deep ripped with a D9 dozer using three tynes and then later ripped with a winged tyne to allow better water capture and infiltration. The topsoil stockpiles are seeded with seed from the annual rehabilitation seeding program, though with the exclusion of tree and larger shrub species. 


\subsection{Preparation of areas for rehabilitation}

The first stage of preparation for rehabilitation is for a survey to be undertaken to create the design of the finished overburden dump which can then be uploaded into the tractor GPS units.

The GPS tractors are used to smooth and shape the batters to the 1:7 design criterion. The smoothing of the batters with the overburden material minimises the amount of subsoil needed to fill any excess on the base design.

Landform designs also recommended containment of any rainfall excess on the top of the dumps to eliminate potential for uncontrolled discharges that could form gullies on the batter slopes. Consequently, the tops of the overburden dumps are split in cells or 'paddies' depending on size and variations in relief. This is done to minimise overburden rehandling to level the paddies. The paddies are levelled to zero fall to eliminate any potential run off accumulation and are surrounded by a bund wall that is approximately $1 \mathrm{~m}$ in height. This bund wall is shaped consistent with the batter designs and is graded so that any rain falling on the top of the batter runs into the paddies and not down the batter.

After the base shaping of the overburden dump is completed, subsoil and topsoil are spread in $200 \mathrm{~mm}$ deep layers respectively. Timber that was stockpiled from the clearing operations is placed on the batters after topsoiling has been completed (Figure 5). This timber is transported to the site with six wheel dump trucks and spread using a D7 with a stick rake attached to the blade for better spreading of the timber.

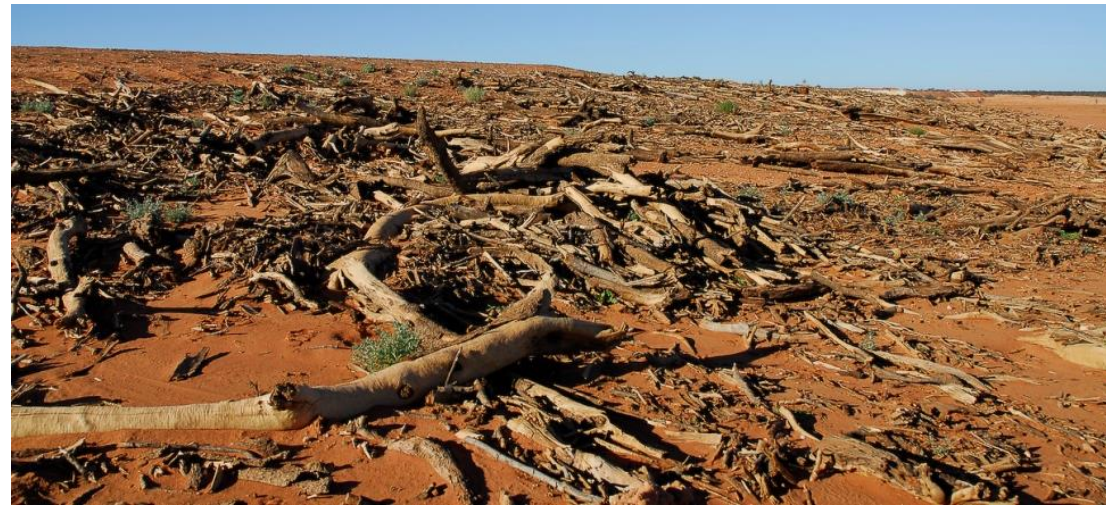

Figure 5 Tree debris spread to reduce surface flow, improve vegetation establishment and provide habitat for small vertebrates

\subsection{Seeding}

Local seeds are collected throughout the year by a contracted seed collector and stored offsite in a seed storage facility. The seed mix available for seeding each year is therefore dependent on what species are locally available and what is stockpiled from previous years.

Seeding of the rehabilitated sites at Ginkgo is completed with a dozer mounted seeder which can operate through the tree debris. The drum seeder is fitted to the ripper box of the dozer, which has the middle tyne removed, so that as the dozer rips the topsoil across the batters, the larger pieces of timber can pass through the undercarriage of the dozer and through the rippers. This also aligns most of the timber across the batter slope, making it more effective in erosion control.

Contour lines for the dozer to follow are pegged by surveyors on $2 \mathrm{~m}$ contours or approximately every 5th or 6th rip line. This allows the lines to be kept very close to contour, which eliminates the risk of water draining along a rip line causing erosion.

\section{$4 \quad$ Assessment of rehabilitation success}

Monitoring of overburden stockpile OB3 (22 ha of batter slopes and 12 ha of pads (dump top areas), Figure 6) was conducted in May, 2010. Nine transects were established on batter slopes and five on pads. 
In addition to the fourteen transects located on OB3, a further six transects have also been located in nearby remnant vegetation (analogue sites). These transects have been established to contemporaneously monitor the condition of the vegetation at the analogue sites so that any major trends evident there can assist with interpretation of results on OB3.

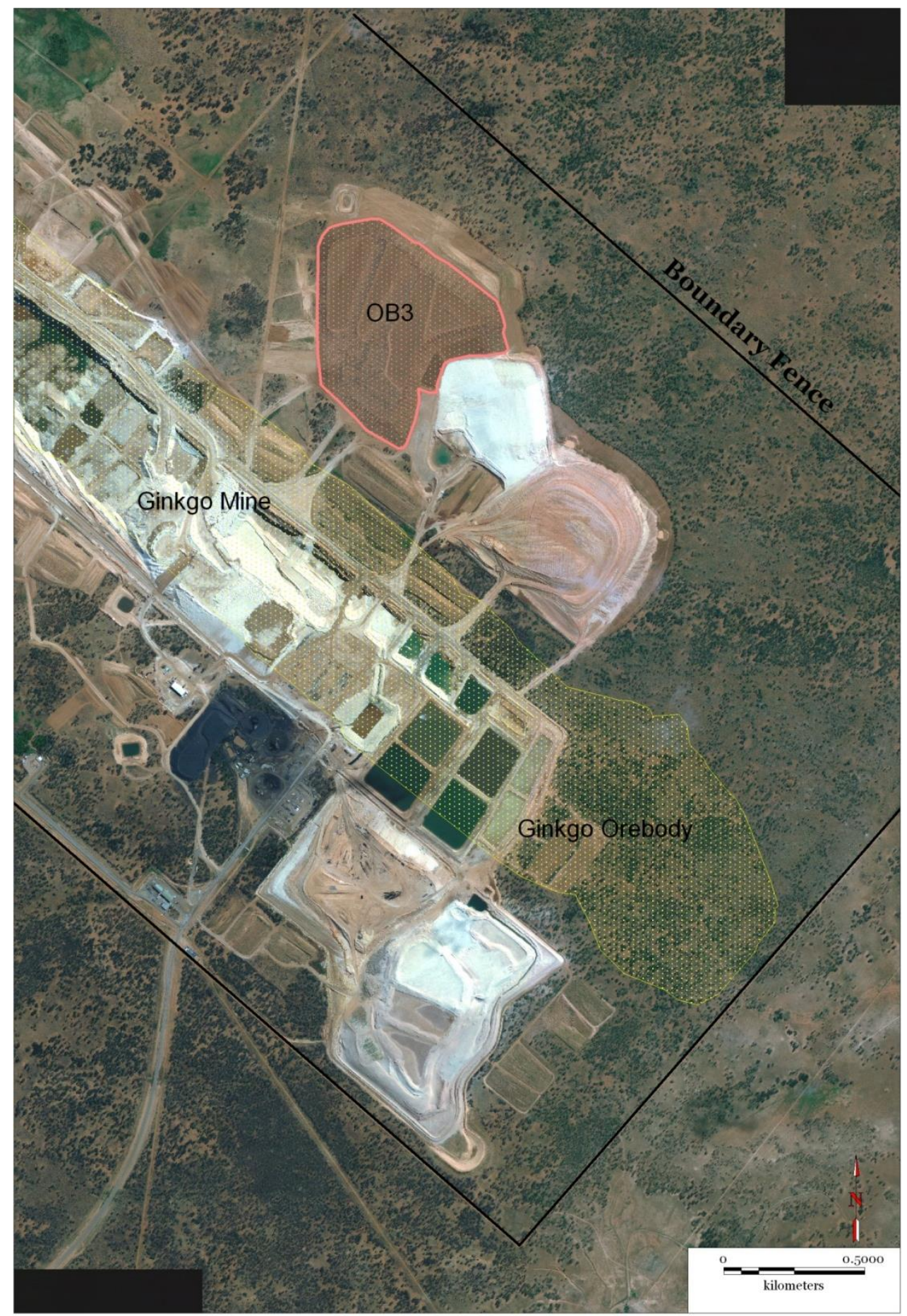

\section{Figure 6 Base map of the Ginkgo Mine showing the mine void and ancillary infrastructure. The rehabilitation site at overburden stockpile OB3 has also been shown}

\subsection{Stability to erosion by water}

Erosion monitoring of the transects on OB3 in May 2010, revealed a remarkably stable environment on both batters and pads. Erosion severity was measured on a scale of 1 (stable, non-eroding surface) to 5 (soil 
surface clearly with common erosion scalds and gullies over $>20 \%$ of soil surface). All five OB3 pad sites had erosion severity values of 1 . Two of nine batter sites scored 1 , with the remaining seven all with values less than 2, with an average score for all sites of 1.3. Erosion, either by wind or water, was considered to be extremely minor at OB3.

The significance of major rainfall events between 2009 and 2011 is also worth mentioning. On more than five occasions during this period at OB3, heavy downpours of more than $200 \mathrm{~mm}$ occurred, yet no significant erosion of topsoil was observed on the batter slopes. One event delivered $100 \mathrm{~mm}$ of rainfall in a one hour period, but the tree debris and vegetation cover on the OB3 batters were sufficient to maintain stability of the newly created desert landform.

\subsection{Vegetation establishment}

Vegetation monitoring of the batter transects showed they are dominated by one major plant taxon Zygophyllum aurantiacum (Figure 7).

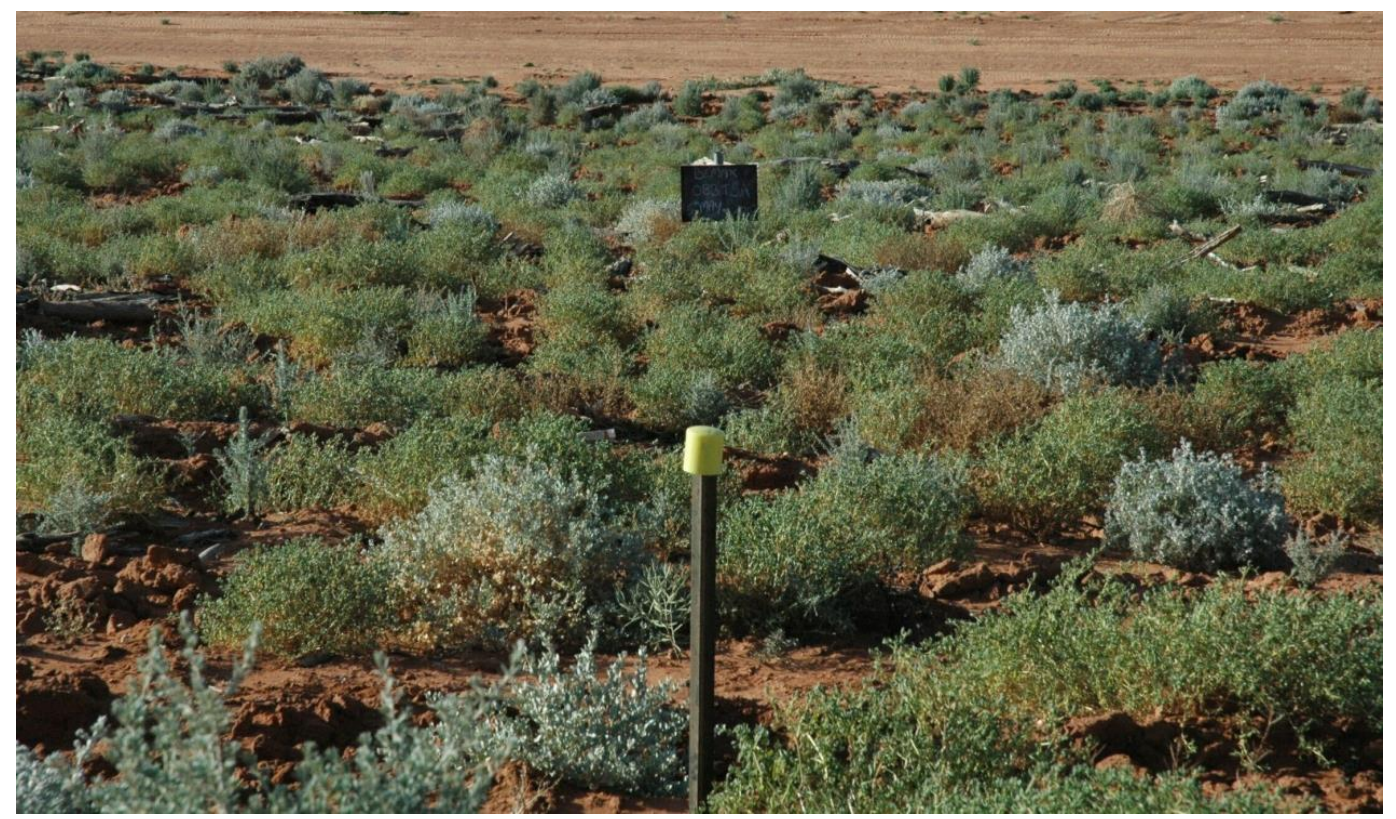

\section{Figure 7 OB3 batter transect May 2010 showing an overwhelming dominance of Zygophyllum aurantiacum}

Batter areas have an average indigenous plant cover of $21.5 \%$ with a range of $15-28 \%$ across the nine transects. This was comprised of an average of 16 taxa with a range across transects of 12 to 25 . Weed taxa were recorded in moderately low numbers with generally less than three taxa per transect. Weed average cover was also low at $2.7 \%$. Both fine and coarse litter incorporation were moderately low at 4.1 and $8.5 \%$ respectively.

Figure 8 provides an illustration of the five most important plant taxa across the batter slope trials. It also shows the percentage contribution of all other taxa recorded in the batter slope transects on OB3. 


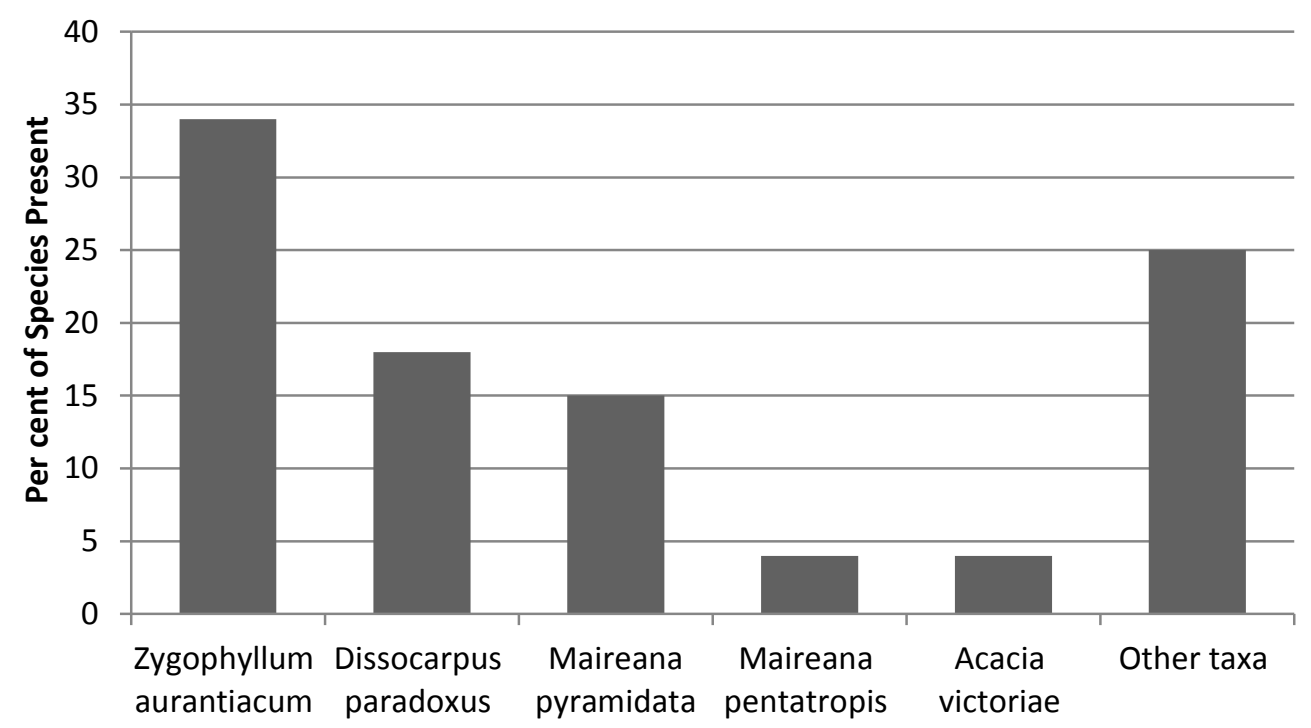

Figure 8 Graph illustrating the five most important plant taxa recorded on batter slopes at OB3. All species were included in the direct seeding mix used for batters

Pad transects are dominated by three plant taxa - Atriplex vesicaria, Maireana pyramidata and Zygophyllum aurantiacum (Figure 9).

Pad transects have an average indigenous plant cover of $20.3 \%$ with a range of $14-27 \%$ across the five transects. This was comprised of an average of 14 taxa per transect with a range across transects of 13 to 18. Weed taxa were recorded in low numbers with generally less than two taxa per transect. Weed average cover was also low at $2 \%$. Fine litter presence was very low at $2.2 \%$ cover whilst coarse litter was not present at all.

Figure 10 provides an illustration of the five major plants across the pad trials. Also shown is the percentage contribution of all other taxa recorded in the pad transects on OB3. It is worth noting that three of the most common plant taxa - Atriplex vesicaria, Zygophyllum aurantiacum and Maireana pyramidata - comprised almost $37 \%$ of the total seed mix by weight.

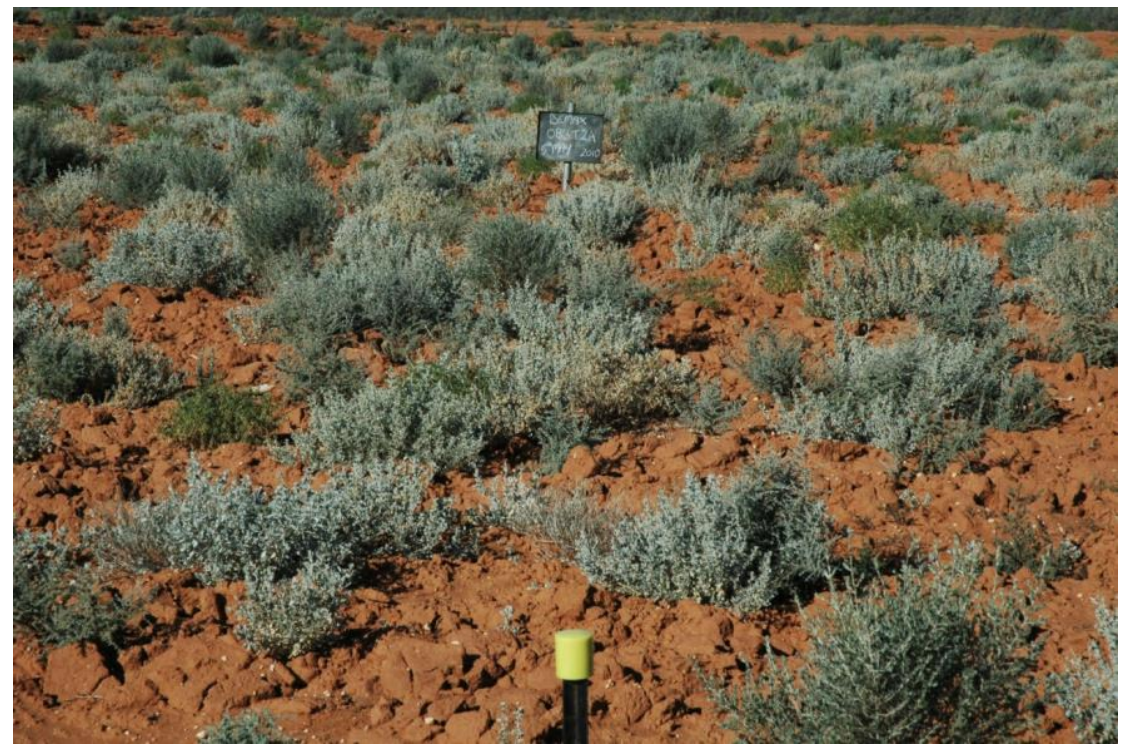

Figure 9 OB3 pad transect May 2010 showing a dominance of chenopod taxa including Atriplex vesicaria and Maireana pyramidata 


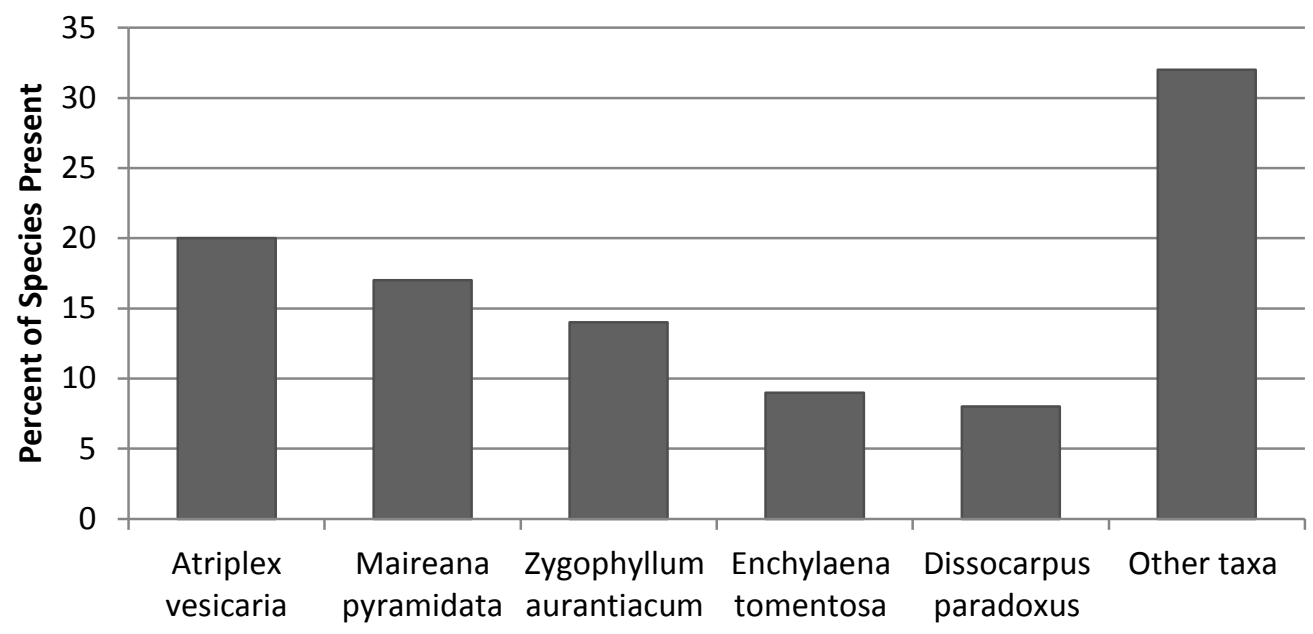

Figure 10 Graph illustrating the five most important plant taxa recorded on pads at OB3. All species were included in the direct seeding mix used for batters

\subsection{Topsoil condition}

Topsoil samples were collected from three locations along the vegetation transects, combined and analysed. Selected results are shown in Table 2.

Table 2 Soil chemistry results from surface $(0-15 \mathrm{~cm})$ samples of vegetation transects at the Ginkgo Mine in May 2010. Values expressed are an average from 9 batter, 5 pad and 6 remnant vegetation transects

\begin{tabular}{lcccccc}
\hline $\begin{array}{l}\text { Transect } \\
\text { Type }\end{array}$ & $\begin{array}{c}\text { Phosphorus } \\
\text { Colwell }\end{array}$ & $\begin{array}{c}\text { Potassium } \\
\text { Colwell }\end{array}$ & $\begin{array}{c}\text { Organic } \\
\text { Carbon }\end{array}$ & $\begin{array}{c}\text { Conductivity } \\
\text { (Saturation } \\
\text { Paste) }\end{array}$ & $\begin{array}{c}\mathrm{pH} \text { Level } \\
\left(\mathrm{CaCl}_{2}\right)\end{array}$ & $\begin{array}{c}\text { Total } \\
\text { Nitrogen }\end{array}$ \\
\hline Batters & $\mathrm{mg} / \mathrm{Kg}$ & $\mathrm{mg} / \mathrm{Kg}$ & $\%$ & $\mathrm{dS} / \mathrm{m}$ & $\mathrm{pH}$ & $\%$ \\
Pads & 8 & 365 & 0.22 & 0.12 & 8.2 & 0.03 \\
Analogue & 7 & 352 & 0.23 & 0.18 & 8.2 & 0.03 \\
\hline
\end{tabular}

The soil chemistry results suggest that the soil stripping, stockpiling and management procedures previously in place with the rehabilitation program have led to:

- An increase in soil pH from 7.5 to 8.2.

- A loss of $\sim 65 \%$ of the soil organic matter.

- A loss of $\sim 50 \%$ of the soil phosphorous (P).

- A loss of $\sim 60 \%$ of the soil nitrogen $(N)$.

The available soil potassium (K) and soil conductivity results for batters and pads are considered to be within normal ranges and are not discussed further.

\subsubsection{Increased soil $\mathrm{pH}$}

Soil $\mathrm{pH}$ is considered to have increased from 7.5 to 8.2 because subsoil, rich in calcrete, has been either erroneously extracted and mixed with topsoil in the soil stripping phase; or subsoil has been mixed with the stored topsoil in the topsoil replacement phase. This occurred during the early stages of topsoil and subsoil stripping at the Ginkgo Mine when less sophisticated machinery was used to gather and move soil. More 
careful attention with better machinery during extraction, storage, removal and ultimately end-placement should avoid this in the future.

\subsubsection{Loss of soil carbon}

The loss of soil carbon is severe within the context of an arid environment. Soil carbon of $0.62 \%$ in the remnant vegetation surface soils is already quite low and probably reflects a long history of grazing on the property by the former land manager. Measured values of $0.23 \%$ are considered very low, and some effort will be required to elevate the soil $C$ levels in the rehabilitation landscape. The low soil $C$ values have potential to severely affect soil chemical and physical properties, with reduced biological activity reducing the stability of soil aggregates whilst also lowering its cation exchange capacity and ability to retain a range of plant nutrients.

\subsubsection{Loss of phosphorus $(P)$ and nitrogen $(N)$}

The levels of soil $P$ and $N$ in the remnant vegetation are low, but levels of $<10 \mathrm{mg} / \mathrm{kg}(\mathrm{P})$ and $0.03 \%(\mathrm{~N})$ in the batters and pads are low and exceedingly low respectively. It may be advisable to target the revegetation of stored topsoil and revegetation areas with more nitrogen-fixing legumes. One of the interesting results of the revegetation program has been the emergence of Lotus cruentus (Red-flowered Trefoil). This short-lived perennial or sometimes annual nitrogen-fixing species will now be used more widely in the revegetation program.

\subsubsection{Importance of perimeter bunding}

Perimeter and cross bunding are used to prevent runoff from the top of the landforms. The tops of the landforms are split into catchment areas (paddies) of approximately 3-5 ha.

At one location, a track on the perimeter bund of the waste dump concentrated flow and discharged it onto the outer batter rather than back onto the dump top (Figure 11). That location represents the only area of incision on the waste dump batter, and highlights the importance of maintaining perimeter and crossbunding.
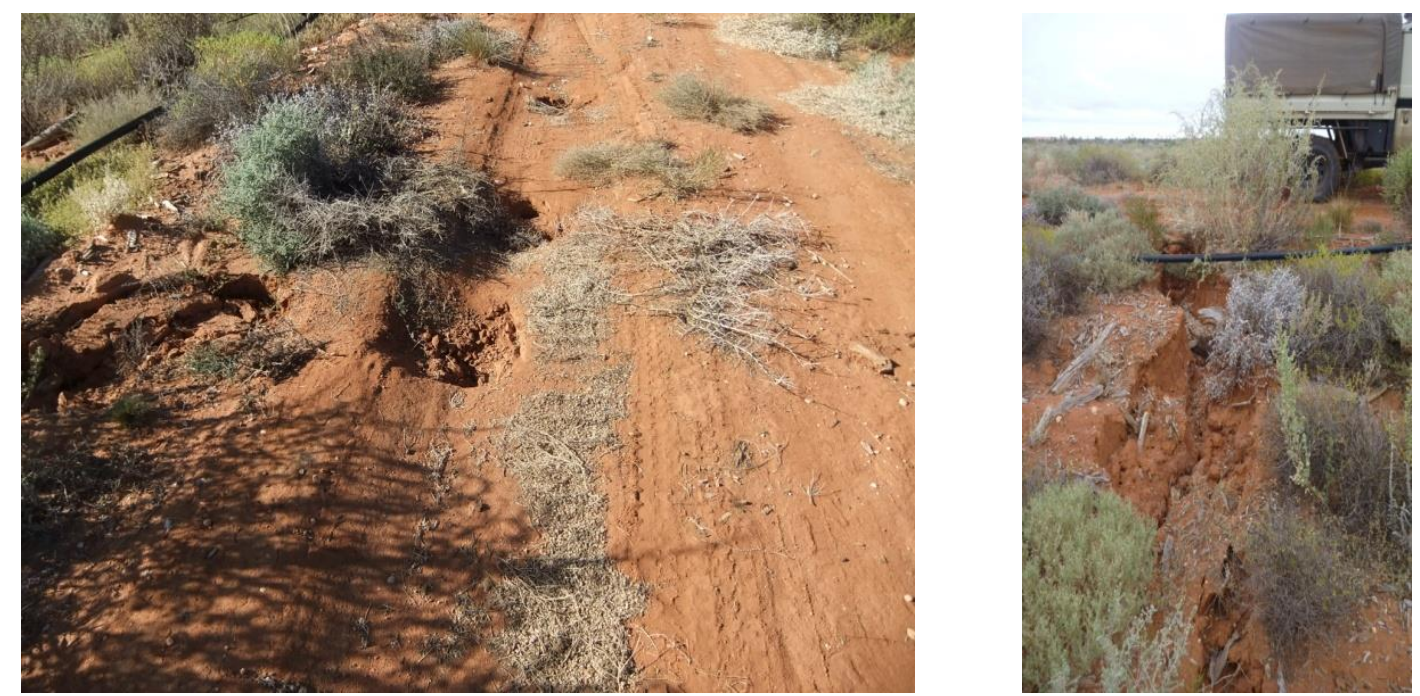

Figure 11 Runoff discharging from perimeter track onto outer batter and causing scour

\subsubsection{Continuing improvement}

Work conducted thus far has achieved satisfactory stability of rehabilitated waste dumps at Ginko. However, continuous improvement will further increase this success by:

- Grading the top of bunds inwards to the paddies to prevent any recurrence of flow discharge as shown in Figure 11. 
- 1:7 maximum gradient of all batters.

- Seeding at the most opportune time (e.g.in early winter not after winter).

- Topsoil management; trialling three cuts of topsoil where possible.

- Maintaining consistent contractors and operators.

It is planned to establish a life of mine soil management program to map, track and monitor topsoil and subsoil removal and placement. This will entail extensive soil surveys and mapping to identify different soils along the mine footprint. These soils can then be stripped and replaced separately depending on associated floristics and material characteristics.

Large scale trials are currently planned with the objective of increasing soil carbon within the rehabilitated landscape, including an annual fertiliser application program until the site (soil) is self-sufficient in nutrients.

Seed sourcing will be investigated with the aim of using more indigenous species from within $100 \mathrm{~km}$ of the site. As well, the monitoring data will be reviewed against seed selection and seeding rates to promote better efficiency and effectiveness of the seeding program.

\section{$5 \quad$ Conclusions}

Rehabilitation operations at the Bemax Ginkgo Mine are distinctive for their success, underpinned by straightforward application of sound science and leading practice in rehabilitation works. All aspects of the rehabilitation operations are carried out to a consistently high standard, with regular review of outcomes, and a commitment to continuous improvement. There is little of what is done at the Ginkgo Mine that has not been widely recommended, but it is rare to see all aspects of planning, implementation, and monitoring applied so effectively.

\section{References}

Benson, J.S., Allen, C.B., Togher, C. and Lemmon, J. (2006) New South Wales Vegetation Classification and Assessment: Part 1 Plant Communities of the NSW Western Plains, Cunninghamia 9(3), pp. 383-450.

Flanagan, D.C., and Livingston, S.J. (1995). Water Erosion Prediction Project (WEPP) Version 95.7 User Summary. In 'WEPP user summary', Flanagan and Livingston (eds), NSERL Report No 11, July 1995.

Renard, K.G., Foster, G.R., Weesies, G.A., McCool, D.K. and Yoder, D.C. (coordinators) (1997) Predicting Soil Erosion by Water: A Guide to Conservation Planning with the Revised Universal Soil Loss Equation (RUSLE), U.S. Department of Agriculture, Agricultural Handbook 703, 404 p. 
